\title{
ANTICANCER EFFECT OF POLYUNSATURATED FATTY ACID EXTRACTS FROM SARDINES ON HUMAN CANCER CELL LINES
}

\author{
R.S. Chitra Som ${ }^{* 1 \& 2}$, Prabha Pillai ${ }^{384}$, S. Lakshmi ${ }^{3}$ and C.K. Radhakrishnan ${ }^{1}$ \\ ${ }^{1}$ Department of Marine Biology, Micobiology and Biochemistry, Cochin University of Science and Technology, \\ Kochi, Kerala, India 682016. \\ ${ }^{2}$ Department of Zoology, N.S.S. College, Main Central Road, Nilamel, Kollam district, Kerala, India 691536. \\ ${ }^{3}$ Department of Molecular Medicine, Regional Cancer Centre, Thiruvananthapuram, Kerala, India 695011. \\ ${ }^{4}$ Department of Zoology, N.S.S. Hindu College, Main Central Road, Perunna, Changanacherry, Kottayam district, \\ Kerala, India 686102 \\ *Corresponding Author Email: chitramarine@yahoo.com

\begin{abstract}
Aim: Investigation and comparison of cytotoxic activity of polyunsaturated fatty acid (PUFA) extracts from two species of marine fishes - Sardinella longiceps and Sardinella fimbriata - abundant in the west coast of India. Methods: Polyunsaturated fatty acid (PUFA) isolated from the fishes were subjected to Gas Chromatography for its quantitative analysis. PUFA isolate from the tissue extracts were used to conduct the study. Cytotoxicity of the PUFA extracts on Cell lines MCF-7 (breast cancer) and DU-145 (prostate cancer) were analyzed. Both cell lines were subjected to MTT Assay with extracts at working concentrations of 100, 200, 400, 800, $1000 \mathrm{\mu g} / \mathrm{ml}$. Results: Both extracts showed significant cytotoxic effects against the two cell lines and a peak cytotoxicity of $85-90 \%$ was apparent. IC-50 values were calculated from the graphs and it was found that $S$. longiceps extracts had a slightly lower IC-50 value indicating that it is cytotoxic to cancer cells invitro even at a lower concentration as compared to extracts from S. fimbriata. Conclusion: Widely available marine fishes like Sardines serve as a rich source of DHA and EPA that are known to reduce the risk of breast and prostate cancer. It is also clear that the extracts from $S$. longiceps which have a higher content of EPA than DHA, and also more widely available in comparison with S. fimbriata, seems to possess greater annihilation effect on both cancer cell lines.
\end{abstract}

\section{KEY WORDS}

Anticancer; PUFA, DHA, EPA, Cytotoxic, Sardinella fimbriata, Sardinella longiceps

\section{INTRODUCTION}

Breast cancer and prostate cancer are the most prevalent malignancies seen in mankind worldwide. According to an Indian health news report, one in 22 women in India is likely to suffer from breast cancer during her lifetime, while the figure is definitely more in the US with one in eight being a victim. Prostate Cancer is the most common non-skin cancer in the world. The frequency of prostate cancer increases exponentially with advancing age and the natural progression to prostate cancer tends to be more aggressive in younger men and those with a family history of the disease. Despite the recent developments in cancer therapy, traditional cancer therapies have multiple limitations, leading to treatment failure, cancer relapse and long term adverse effects [1]. These limitations are mainly related to drug resistance by tumor cells and high regeneration potential of cancer stem cells. Hence, it is imperative that more research is expended in finding sources of naturally available anti-cancerous compounds which can aid drugs against breast and prostate cancer with little or no toxicity on normal cells 
Nutrition influences cancer etiology in about 35\% of cancer cases. Human epidemiologic studies have shown that dietary intake of fish oil may protect against the development of certain cancers including breast, colon, and prostate [2]. Reported benefits of n-3 PUFA dietary supplements given before or during cancer therapy include reversing tumor cell drug resistance [3]; reducing the gastrointestinal, hematological, or cardiac side effects of various chemotherapeutic treatments [4]. The results of in vitro studies have shown that a small amount of either EPA or of DHA added to cell culture medium can cause tumor cell death but not kill cultured normal cells [5-8]. It is therefore believed that one or both of these n-3 fatty acids is responsible for the beneficial effects of fish oil against tumor growth.

Most cancer studies on PUFA or fish oil have not distinguished between EPA and DHA $s$ assuming that both have similar biochemical effects. Some studies reported a similar, but slightly subdued, effect of DHA as compared to EPA and hypothesized that this could be partly due to retro-conversion to EPA [7]. The objective of this study was to determine the cytotoxicity on breast cancer cells (MCF-7) of PUFA extracts from two different species of Sardines, viz. S. fimbriata and S. longiceps, found in the same area within their ranges. Comparison of their respective PUFA profile with the degree of cytotoxicity is also attempted.

\section{MATERIALS AND METHODS}

\section{Fish samples}

Fresh samples of $S$. longiceps and S. fimbriata, were collected from the Kaalamukku landing centre $\left(9^{\circ} 58^{\prime} 57^{\prime \prime} N, 76^{\circ} 14^{\prime} 33^{\prime \prime} E\right)$ at Kochi. Samples were washed in sterile water and brought to the laboratory in an ice box within 30 minutes after collection.

\section{Preparation of extracts}

The internal organs were removed and the meat sliced. Slices were blended and centrifuged at 10,000 rpm for 15 minutes. Post centrifugation, the oil phase was separated and saponified for converting the triglycerides to free fatty acids. The fatty acid mixture was subjected to Urea Complexing [9] and subsequently to low temperature fractional crystallization [10] to obtain a mixture of substantially pure PUFA.

\section{Determination of Fatty acid composition}

The composition of the PUFA in the above mixture was directly analysed by Gas Chromatography (GC) using fatty acid methyl ester (FAME) method [11]. The fatty acids were separated by gas liquid chromatography (Thermo Trace GC Ultra) equipped with a capillary column (30m long and $0.54 \mathrm{~mm}$ diameter) and a flame ionization detector in the presence of hydrogen and air. Nitrogen was used as the carrier gas at a flow rate of $0.8 \mathrm{ml} / \mathrm{min}$. Initial temperature was set at $70^{\circ} \mathrm{C}$ and was increased at a rate of $3^{\circ} \mathrm{C} / \mathrm{min}$ until peak temperature of $250^{\circ} \mathrm{C}$ was reached. Injector and detector temperatures were kept at $260^{\circ} \mathrm{C}$ and $275^{\circ} \mathrm{C}$ respectively. Fatty acids separated were identified by the comparison of retention times with those obtained by the separation of a mixture of standard fatty acids. Measurement of peak areas and data processing were carried out by Thermo Chrom card software. Individual fatty acids were expressed as a percentage of total fatty acids.

\section{Cell Culture}

Cancer cell lines MCF-7 and DU-145 were obtained from National Centre for Cell Science (NCCS), Pune, India, and cell culture supplies were purchased from $\mathrm{Hi}$ Media Laboratories (Mumbai, India). Cells were maintained at $37^{\circ} \mathrm{C}$ under $5 \% \mathrm{CO}_{2}$ in Dulbecco's Modified Eagle Medium (DMEM) supplemented with $10 \%$ Fetal Bovine Serum (FBS), $100 \mathrm{U} / \mathrm{ml}$ penicillin and $100 \mathrm{U} / \mathrm{ml}$ streptomycin. The culture medium was changed every 2 days and the cells were sub-cultured every 6 days.

\section{Assessment of Cell Viability}

Cell viability was determined using MTT (3- (4, 5dimethylthiazol-2yl)-2, 5- diphenyltetrazolium bromide) assay [12]. In order to detect the cytotoxicity of the fish oil extracts, both cell lines were treated with the extract at different concentrations for a specified incubation time. The intensity of formazan, reduced product of MTT after reaction with active mitochondria of live cells, was determined by measuring the absorbance in a 96well microplate reader (Bio-Tek, Powerwave XS, USA). Results were expressed as percentage inhibition considering absorbance control cells as $100 \%$ viable. Seeded MCF-7 (breast cancer) and DU-145 (prostate cancer) cell lines at a density of 5000 cells/well $(100 \mu \mathrm{l}$ each) in a 96 well microplate and grown in a $5 \% \mathrm{CO}_{2}$ incubator at $37^{\circ} \mathrm{C}$. When cells had adhered and were about $50 \%$ confluent, the serially diluted concentrations of the cytotoxin $(100 \mu \mathrm{l}$ each) were added to the wells to get the final concentration of 100, 200,400,600, 800 $1000 \mu \mathrm{g} / \mathrm{ml}$. Control wells were devoid of toxin and replaced with DMSO to get the final concentration of $1 \%$. 
After 72 hrs incubation in $\mathrm{CO}_{2}$ incubator at $370 \mathrm{C}$, aspirated out $200 \mu$ l of solution from the wells without disturbing the cells and added $100 \mu$ l of MTT at a concentration of $1 \mathrm{mg} / \mathrm{ml}$ of $10 \%$ DMEM. Incubated in dark for $2 \mathrm{hrs}$ in $\mathrm{CO}_{2}$ incubator at 370 C. Added $100 \mu \mathrm{l}$ lysis buffer to dissolve the formazan crystals and incubated in dark for another $4 \mathrm{hrs}$. Read the plate on ELISA reader at a wavelength of $570 \mathrm{~nm}$ to measure optical density (OD).

Calculated percentage of cytotoxicity as per the below formula

Cytotoxicity = $100-$ treated OD/control OD x 100 .

\section{Statistical Analysis}

The obtained results were analyzed using 1-way ANOVA [13] against the control followed by Fisher's LSD test and $p<0.01$ was considered as significant.

\section{RESULTS \& DISCUSSION}

The respective cytotoxicity profiles of the two species for MCF-7 are illustrated in Fig: 1 and values indicated in Table: 1; and for DU-145 are illustrated in Fig: 2 and Table: 2; statistically, the means for each of the concentrations were found to be significant with $p<$ 0.01 .

Table: 3 tabulates the IC-50 values of the two extracts against both cell lines, along with peak values and corresponding concentrations. It can be seen that the peak effects for both species is around $86 \%$ for MCF-7 and around $90 \%$ for DU-145. For extracts from $S$. longiceps, the peak effect happens at a concentration of $200 \mu \mathrm{g} / \mathrm{ml}$ for both MCF-7 and DU-145. At $200 \mu \mathrm{g} / \mathrm{ml}$, extracts from $S$. fimbriata show peak activity for DU-145 while a concentration of $400 \mu \mathrm{g} / \mathrm{ml}$ is required for the same extract to show peak effect for MCF-7.

\begin{tabular}{lllll}
\hline \multicolumn{5}{c}{ Table 1: Activity of PUFA extracts of S. longiceps and S. fimbriata on MCF-7 at different concentrations } \\
\hline Conc. & Sardinella longiceps & & Sardinella fimbriata & \\
\cline { 2 - 5 } & OD Mean \pm SD & Cytotoxicity & OD Mean \pm SD & Cytotoxicity \\
\hline 0 & $2.77 \pm 0.07$ & 0.00 & $2.77 \pm 0.07$ & 0.00 \\
100 & $1.06 \pm 0.06$ & 61.50 & $2.38 \pm 0.03$ & 14.02 \\
200 & $0.38 \pm 0.01$ & 86.20 & $1.18 \pm 0.03$ & 57.21 \\
400 & $0.41 \pm 0.03$ & 85.19 & $0.38 \pm 0.03$ & 86.24 \\
600 & $0.44 \pm 0.02$ & 83.79 & $0.38 \pm 0.01$ & 86.20 \\
800 & $0.54 \pm 0.03$ & 80.47 & $0.4 \pm 0.01$ & 85.24 \\
1000 & $0.58 \pm 0.03$ & 78.92 & $0.38 \pm 0.01$ & 85.94 \\
\hline
\end{tabular}

Table 2: Activity of PUFA extracts of S. longiceps and S. fimbriata on DU-145 at different concentrations

\begin{tabular}{lllll}
\hline \multirow{2}{*}{ Conc. } & \multicolumn{3}{c}{ Sardinella longiceps } & \multicolumn{3}{l}{ Sardinella fimbriata } \\
\cline { 2 - 5 } & OD Mean \pm SD & Cytotoxicity & OD Mean \pm SD & Cytotoxicity \\
\hline 0 & $2.18 \pm 0.08$ & 0.00 & $2.18 \pm 0.08$ & 0.00 \\
100 & $0.25 \pm 0.08$ & 88.11 & $0.54 \pm 0.55$ & 74.83 \\
200 & $0.22 \pm 0.01$ & 89.73 & $0.2 \pm 0.04$ & 90.41 \\
400 & $0.25 \pm 0$ & 88.35 & $0.21 \pm 0$ & 90.18 \\
600 & $0.32 \pm 0.04$ & 85.09 & $0.22 \pm 0.01$ & 89.93 \\
800 & $0.35 \pm 0.01$ & 83.80 & $0.23 \pm 0.03$ & 89.13 \\
1000 & $0.37 \pm 0.01$ & 82.83 & $0.33 \pm 0.11$ & 84.52 \\
\hline
\end{tabular}

Table 3: Summary of the cytotoxic activity of PUFA extracts on MCF-7 and DU-145 cell lines

\begin{tabular}{lll}
\hline Parameters & S. fimbriata & S. longiceps \\
\hline IC50 (MCF-7) & $180.01 \mu \mathrm{g} / \mathrm{ml}$ & $81.17 \mu \mathrm{g} / \mathrm{ml}$ \\
IC50 (DU-145) & $67.64 \mu \mathrm{g} / \mathrm{ml}$ & $53.07 \mu \mathrm{g} / \mathrm{ml}$ \\
Peak Cytotoxicity (MCF-7) & $86.28 \%$ & $86.30 \%$ \\
Peak Cytotoxicity (DU-145) & $90.41 \%$ & $89.73 \%$ \\
Concentration at Peak (MCF-7) & $400 \mu \mathrm{g} / \mathrm{ml}$ & $200 \mu \mathrm{g} / \mathrm{ml}$ \\
Concentration at Peak (DU-145) & $200 \mu \mathrm{g} / \mathrm{ml}$ & $200 \mu \mathrm{g} / \mathrm{ml}$ \\
\% EPA & $32.52 \%$ & $55.54 \%$ \\
\% DHA & $65.82 \%$ & $24.02 \%$ \\
EPA:DHA Ratio & $3: 8$ & $3: 2$ \\
\hline
\end{tabular}




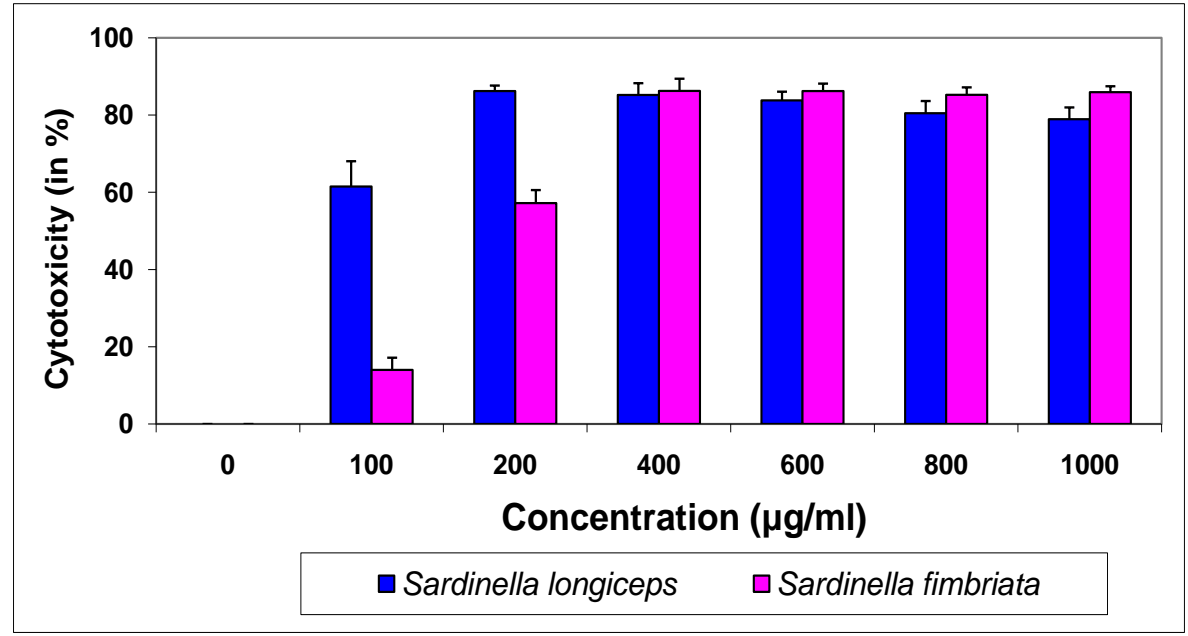

Fig 1: Cytotoxic Activity of PUFA extracts from S. longiceps and S. fimbriata on MCF-7 cell line

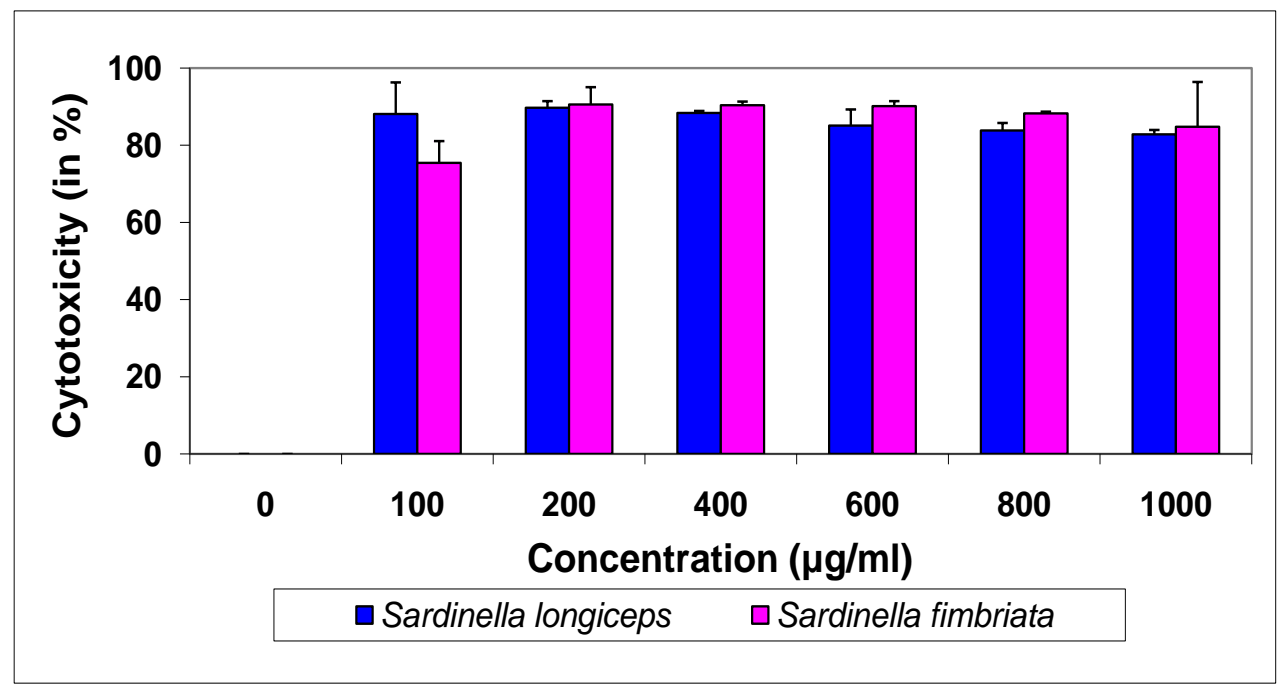

Fig 2: Cytotoxic activity of PUFA extracts from S. longiceps and S. fimbriata on DU-145 cell line

The PUFA extracts were analyzed by GC to identify the fatty acids present in the extract. The major compounds identified were unsaturated fatty acids ranging from C20 to C24 with a preponderance of C20:5 (EPA) and C22:6 (DHA) PUFA. GC analyses of the PUFA from the fish S. longiceps showed an EPA presence of $55.54 \%$ and a DHA presence of $32.52 \%$. The GC analyses of the PUFA from the fish $S$. fimbriata gave a much lower EPA figure of $24.02 \%$ but a correspondingly higher DHA value of $65.82 \%$. To correlate with the concentrations of EPA and DHA in both the extracts, values obtained from Gas Chromatography are also included in Table: 3.

The results showed that both the fish oil extracts have a great degree of cytotoxic effects on MCF-7 and DU-145 cells of the order of $86-90 \%$ at the peak - the activity itself being dose dependent at lower concentrations. The $\mathrm{IC}_{50}$ value of sardine oil emulsion on human breast cancer cell line MCF-7 was as high as $1000 \mu \mathrm{g} / \mathrm{ml}$ [14], while it is evident that substantially pure PUFA from our experiments have a much stronger cytotoxic effect which is an order less than prior studies $-180 \mu \mathrm{g} / \mathrm{ml}$ for S. fimbriata and $81 \mu \mathrm{g} / \mathrm{ml}$ for $S$. longiceps. It can also be concluded that the EPA-rich S. longiceps extracts have a greater cytotoxic effect on MCF-7 cells at lower concentrations as compared to the DHA-rich $S$. fimbriata as evident from the $\mathrm{IC}_{50}$ values. This is also true to lesser extent for DU-145 cells too.

Though there are no established studies proving EPA to be more toxic against MCF-7 and DU-145 as compared to DHA, it was believed until recently that the action of DHA is mostly by retro-converting to EPA. Hence, the action of DHA on the annihilation of cancer cells could be delayed until the conversion happens [7]. However, recent evidences indicate that the action of both EPA and DHA could be very different and differs with different cell lines. 
Many mechanisms have been proposed for suppression of tumor cell growth by n-3 fatty acids, and new mechanisms are frequently reported as additional knowledge is gained of the regulation of gene expression by fatty acids. It is likely that suppression of tumor cell growth by $n-3$ fatty acids is due to the combination of these mechanisms rather than a single, unique activity that is the sole mechanism of action [15]. The formation of cytostatic and cytotoxic compounds after peroxidation of long chain PUFAs has been proposed as the primary mechanism for the activity of n-3 PUFAs against cancers [16-18]. Other mechanisms proposed include the alteration in prostaglandin synthesis [19], alteration in gene transcription [20], suppression of $n-6$ fatty acid transport [21], and modulation of antioxidant enzymes(AOE) and of apoptosis [22]. EPA inhibits NF-KB activation and IL-6 production in cancer cells, and there by induce apoptosis [23]. These effects of EPA might have benefitted in achieving improved cytotoxic potential by the PUFA extract from $S$. longiceps as revealed by our study. It may also be noted that in both extracts, the cytotoxicity marginally decreases after attaining the peak value at a specific concentration - though this phenomenon is unknown among normal drugs, it is displayed by several natural compounds [24].

\section{CONCLUSION}

In conclusion, widely available marine fishes like Sardines serve as a rich source of DHA and EPA that are known to reduce the risk of breast and prostate cancer. These fish oils also have the ability to control the proliferation of cancer cells and hence are potential drug sources for oncologic pharmaceuticals. It is also clear that the extracts from $S$. longiceps which have a higher content of EPA than DHA, and also more widely available in comparison with $S$. fimbriata, seems to possess greater annihilation power. Mechanism of action of these two compounds is still subject of further study and can vary between cancer cell lines. Such an in-depth study probably will give more insights into the right combination of these fatty acids to be applied for faster impact on different cancer cell lines. This will also mould how pharmaceutical industry will convert these widely available raw materials as drug sources and also as adjuvants, to improve the efficacy and tolerability of traditional anticancer therapies.

\section{ACKNOWLEDGEMENTS}

This work was supported by Cochin University of Science and Technology and CSRS \& CKR would like to acknowledge the same.

\section{References}

1. Murphy, R.A., Mourtzakis, M., Chu, Q.S., Baracos, V.E., Reiman, T., Mazurak, V.C., Supplementation with fish oil increases first-line chemotherapy efficacy in patients with advanced non-small cell lung cancer. Cancer, 117:3774-3780 (2011).

2. Sczaniecka, A.K., Brasky, T.M., Lampe, J.W., Patterson, R.E., White, E., Dietary intake of specific fatty acids and breast cancer risk among postmenopausal women in the VITAL cohort. Nutrition and Cancer, 64:1131-42 (2012).

3. Muscaritoli, M., Molfino, A., Gioia, G., The 'parallel pathway': a novel nutritional and metabolic approach to cancer patients. Intern Emerg Med, 6:105-112, (2011).

4. Hardman,WE., Moyer, M.P., Cameron, I.L., Fish oil supplementation enhanced CPT-11 (Irinotecan) efficacy against MCF7 breast carcinoma xenografts and ameliorated intestinal side effects. Br. J. Cancer, 81: 440448, (1999).

5. de Vries, C.E.E., Van Noorden, C.J.F., Effects of dietary fatty acid composition on tumor growth and metastasis. Anticancer Res, 12: 1513-1522, (1992).

6. Begin, M.E., Ells, G., Das, U.N., Horrobin, D.F., Differential killing of human carcinoma cells supplemented with $n-3$ and $\mathrm{n}-6$ polyunsaturated fatty acids. J Natl Cancer, 77:1053-1062, (1986).

7. Price, S.A., Tisdale, M.J., Mechanism of inhibition of a tumor lipid-mobilizing factor by eicosapentaenoic acid. Cancer Res, 58: 4827-4831, (1998).

8. de Salis, H.M., Meckling-Gill, K.A., EPA and DHA alter nucleoside drug and doxorubicin toxicity in L1210 cells but not in normal murine S1 macrophages. Cell. Pharmacol, 2: 69-74, (1995).

9. Rubin, D., Rubin, E.J., Method of extraction and purification of polyunsaturated fatty acids from natural sources. United States Century Laboratories, Inc. (Port Washington, NY) 4792418, (1988).

10. Markley, K. S., Techniques of Separation: A. Distillation, Salt Solubility, Low Temperature Crystallization. Fatty Acids, 3: 2081-2123, (1964).

11. Mondello, L., Tranchida, P.Q., Dugo, P., Dugo, G., Rapid, micro-scale preparation and very fast gas chromatographic separation of cod liver oil fatty acid methyl esters. Journal of Pharmaceuticals and Biomedical Research, 41:1566-1570, (2006).

12. Mosmann, T., Rapid colorimetric assay of celluar growth and survival: $A$ application to proliferation and cytotoxicity assays. Journal of immunology method, 65 : 55-63, (1983). 
13. Zar, J.H., Biostatistical Analysis (Prentice -Hall Inc.USA), (1984).

14. Ueda, K., Asai, Y., Yoshimura, Y., Iwakawa, S., Effect of oio-in-water lipid emulsions prepared with fish oil or soybean oil on the growth of MCF-7 cells HepG2 cells. Journal of Paharmocology, 60: 1069-1075, (2007).

15. Hardman, W.E., n-3 Fatty Acids and Cancer Therapy. The American Society for Nutritional Sciences Journal, 134:3427-3430, (2004).

16. Gonzalez, M.J., Schemmel, R.A., Gray, J.I., Dugan, L.J., Sheffield, L.G., Welsch, C.W., Effect of dietary fat on growth of MCF-7 and MDA-MB231 human breast carcinomas in athymic nude mice: relationship between carcinoma growth and lipid peroxidation product levels. Carcinogenesis, 12: 1231-1235, (1991).

17. Gonzalez, M.J., Fish oil, lipid peroxidation and mammary tumor growth. Journal of American College of Nutrition, 14: 325-335, (1995).

18. Das, U.N., Y-linolenic acid, arachidonic acid, and eicosapentaenoic acid as potential anticancer drugs. Nutrition, 6: 429-434, (1990).

19. Rose, D.P., Rayburn, J., Hatala, M.A., Connolly, J.M., Effects of dietary fish oil on fatty acids and eicosanoids in metastasizing human breast cancer cells. Nutrition and Cancer, 22: 131-141, (1994).

20. Jump, D.B, Clarke, S.D., Regulation of gene expression by dietary fat. Annual Review Nutrition, 19: 63-90, (1999).

21. Sauer, L.A., Dauchy, R.T., Blask, D.E., Mechanism for the antitumor and anticachectic effects of n-3 fatty acids. Cancer Research, 60: 5289-5295, (2000).

22. Fernández-Bañares ,F., Esteve ,M., Navarro, E., Cabré, E., Boix ,J., Abad-Lacruz, A., Klaassen, J.,, Planas R., Humbert,. P, Pastor, C., Gassull, M.A., Changes of the mucosal $n 3$ and $n 6$ fatty acid status occur early in the colorectal adenoma-carcinoma sequence. Gut, 38: 254 59, (1996).

23. Kubota, H.I, Matsumoto, H., Higashida, M., Murakami, H., Nakashima, H., Oka, Y., Okumura, H., Yamamura. M., Nakamura, M., Hirai, T., Eicosapentaenoic acid modifies cytokine activity and inhibits cell proliferation in an oesophageal cancer cell line. Anticancer Research, 33(10):4319-4324, (2013).

24. Scheim, D.E., Cytotoxicity of unsaturated fatty acids in fresh human tumor explants: concentration thresholds and implications for clinical efficacy. Lipids in Health and Disease, 8: 54, (2009).
*Corresponding Author:

R.S. Chitra Som ${ }^{*}$ et al

Email:chitramarine@yahoo.com 